\title{
A Problematic Case of Unclassified Multicystic Biliary Tumor with Adenofibroma Features
}

To the Editor,

Biliary adenofibroma (BFA) was first described by Tsui et al. (1). Since then, few cases of BFA of the liver have been reported in the literature (1-8). It is characterized by tubulocystic proliferation of variable-sized neoplastic ducts embedded in abundant fibrous stroma. The typical case of biliary adenofibroma shows a non-mucin secreting and apocrine-like epithelium that expresses biliary cytokeratins (CK7, CK19), suggesting a bile duct origin $(1,6)$. In this report, we describe a case of biliary multicystic tumor with adenofibroma features, which did not fit any current classification of biliary tumor.

A 23-year-old man who had a past history of left orchiectomy and chemotherapy for a testicular germ cell tumor was admitted to our institution for routine follow-up controls. Physical examination on admission was unremarkable. However, a well-circumscribed multicystic mass lesion in the liver containing solid areas was detected on abdominal computerized tomography (CT). Although tumor markers as well as hematologic and coagulation tests were within the normal ranges, the patient underwent partial hepatectomy with preoperative diagnosis of germ cell tumor metastasis to the liver.

In the resection specimen, a mass measuring approximately $6 \times 3 \mathrm{~cm}$ was detected in the liver parenchyma. In the cut section, an unencapsulated but well-circumscribed multicystic tumor containing solid areas was observed. The cysts contained serous and hemorrhagic fluid. Solid areas were white in color and composed of microcysts leading to a sponge-like appearance.

Histopathological findings are presented in Figure 1A-G. The cyst locules were not communicating and were lined by columnar, cuboidal and flattened epithelium. Mucin production was not present by mucicarmine histochemical staining. A moderate to high epithelial atypia was observed in some areas. However, atypical mitosis was not present. In some areas, papillary growths and apocrine snouts were also evident. The stroma beneath the epithelium was fibrous and no ovarian-like stroma was detected. The solid areas consisted of smaller tubules and glands embedded in a denser collagenous background.

In the immunohistochemical examination, tumor cells displayed positivity with CK7, CK19, CK 18 and EMA.
AFP, PLAP, HCG, Hepatocyte, CK20, CD30, OCT4 and MUC2 were negative (Figure $1 A-G$ ).

Considering the past history of the patient, the possibility of testicular germ cell tumor metastasis was first to be excluded. This was not troublesome, because the histopathological features and immunohistochemistry did not support a metastatic germ cell tumor.

The gross multicystic appearance of the presented tumor was reminiscent of an intrahepatic multicystic biliary hamartoma. The tumor was composed of neoplastic cysts and fibrous stroma only whereas multicystic biliary hamartoma is composed of ducts, periductal glands and connective tissue (8).

The Von-Meyenberg complex with its smaller size and periportal localization was easily excluded. The findings of the present tumor were also completely different from a ciliated foregut cyst (8).

The presence of multiple cysts and papillary projections together with solid areas leaded us to consider mucinous cystic neoplasia (MCN) and intraductal papillary neoplasms (IPN) of the biliary tree in the differential diagnosis. However, the absence of ovarian like-stroma and the non-communicant nature of the cysts did not fit the diagnostic criteria of MCN and IPN, respectively (9-11). Furthermore, tumors cells were negative for both MUC-2 and mucicarmine. The tumor did not show the morphology of the solid component of malignant MCN composed of tubulopapillary carcinoma or cholangiocarcinoma. Therefore, other current classifications of biliary cystic tumors such as MCNs or IPNs seemed inappropriate for our case.

In the tumor presented here, solid areas showed characteristics of BFA such as dense fibrous stroma and apocrine snouts $(1,6)$. On the other hand, marked cellular atypia was not consistent with BFA, because it is considered a benign tumor. However, the first report of biliary adenofibroma documented that moderate atypia was evident in some cysts similar to the present tumor (1). Additionally, two out of seven reported recent cases showed malignant transformation $(2,3)$ and one of them showed local recurrence and distant metastases $(3,8)$. That is why our diagnosis was in the direction of biliary fibroadenoma despite the presence of cellular atypia. The expression of 

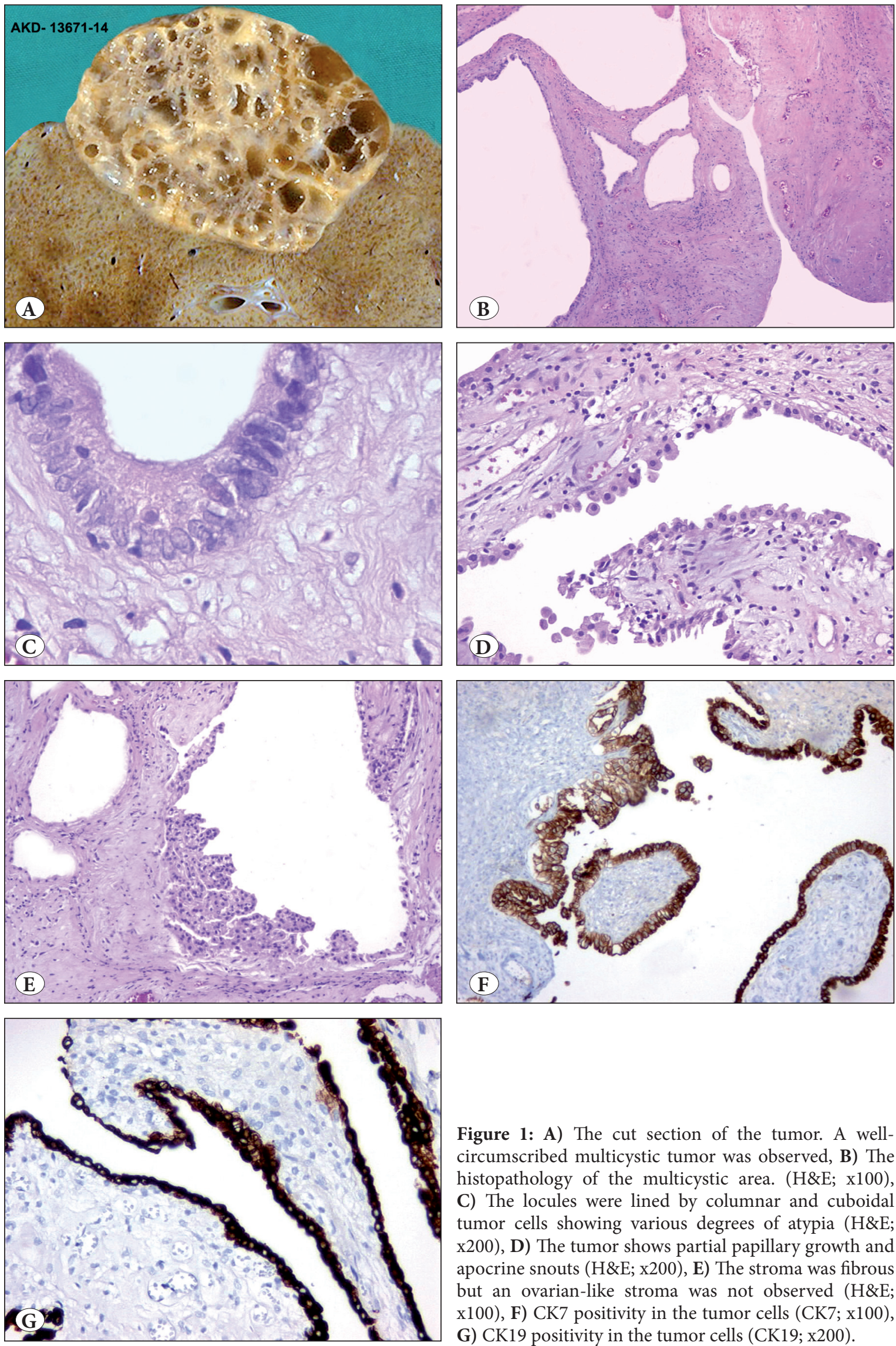

Figure 1: A) The cut section of the tumor. A wellcircumscribed multicystic tumor was observed, B) The histopathology of the multicystic area. (H\&E; x100), C) The locules were lined by columnar and cuboidal tumor cells showing various degrees of atypia (H\&E; $\mathrm{x} 200$ ), D) The tumor shows partial papillary growth and apocrine snouts (H\&E; x200), E) The stroma was fibrous but an ovarian-like stroma was not observed (H\&E; $\mathrm{x} 100)$, F) CK7 positivity in the tumor cells (CK7; x100), G) CK19 positivity in the tumor cells (CK19; x200). 
CK7, CK19 and CK 18 also supported the bile duct origin of this tumor. However, the present tumor displays two features that are not consistent with BFA. Macroscopic appearance of the tumor is not microcystic and solid like BFA and the papillary component is less pronounced than BFA as reported by Kai et al. (8). Therefore, the tumor was diagnosed as unclassified multicystic biliary tumor with adenofibroma features.

Although this tumor is extremely rare, we expect the appropriate classification will be developed by the accumulation of similar cases and studies that reveal the nature of this kind of neoplasm.

\section{REFERENCES}

1. Tsui WM, Loo KT, Chow LT, Tse CC. Biliary adenofibroma. A heretofore unrecognized benign biliary tumor of the liver. Am J Surg Pathol. 1993;17:186-92.

2. Haberal AN, Bilezikçi B, Demirhan B. Malignant transformation of biliary adenofibroma: A case report. Turk J Gastroenterol. 2001;12:149-53.

3. Akin O, Coskun M. Biliary adenofibroma with malignant transformation and pulmonary metastases: CT findings. Am J Roentgenol. 2002;179:280-1.

4. Garduno-Lopez AL, Mondragon-Sanchez R, Bernal-Maldonado R, Hinojosa-Becerril CA, Meneses-García A. A case of biliary adenofibroma of the liver causing elevated serum CA 19-9 levels. Clin Transl Oncol. 2002;4:271-3.

5. Parada LA, Bardi G, Hallén M, Hägerstrand I, Tranberg KG, Mitelman F, Johansson B. Monosomy 22 in a case of biliary adenofibroma. Cancer Genet Cytogenet. 1997;93:183-4.

6. Varnholt H, Vauthey JN, Dal Cin P, Marsh Rde W, Bhathal PS, Hughes NR, Lauwers GY. Biliary adenofibroma: A rare neoplasm of bile duct origin with an indolent behavior. Am J Surg Pathol. 2003;27:693-8.
7. Gurrera A, Alaggio R, Leone G, Aprile G, Magro G. Biliary adenofibroma of the liver: Report of a case and review of the literature. Patholog Res Int. 2010;2010:504584.

8. Kai K, Yakabe T, Kohya N, Miyoshi A, Iwane S, Mizuta T, Miyazaki $\mathrm{K}$, Tokunaga O. A case of unclassified multicystic biliary tumor with biliary adenofibroma features. Pathol Int. 2012;62:506-10.

9. AFIP Atlas of tumor pathology, third series tumors of the liver and intrahepatic bile ducts. Ishak KG, Goodman ZD, Stocker JT, editors. Washington, DC: Armed Forces Institute of Pathology, 1999;263-5.

10. Devaney K, Goodman ZD, Ishak KG. Hepatobiliary cystadenoma and cystadenocarcinoma. A light microscopic and immunohistochemical study of 70 patients. Am J Surg Pathol. 1994;18:1078-91.

11. WHO Classification of Tumors of the Digestive System. Bosman FT, Carnerio F, Hruban RH, Theise ND, editors. Lyon: International Agency for Research on Cancer. 2010;236-8.

\section{Gülsüm Özlem ELPEK}

Department of Pathology, Akdeniz University, School of Medicine, ANTALYA, TURKEY

\section{Betül ÜNAL}

Department of Pathology, Akdeniz University, School of Medicine, ANTALYA, TURKEY

E-mail: betulunalmd@gmail.com

Phone: +90 2422496384

\section{Cumhur İbrahim BASSSORGUN}

Department of Pathology, Akdeniz University, School of Medicine, ANTALYA, TURKEY

\section{Erdem AYIK}

Department of Pathology, Akdeniz University, School of Medicine, ANTALYA, TURKEY 